\title{
Postpartum Minor Health Problems Encountered among Women and Neonates Undergoing Cesarean Section at Women's Health Center - Assiut University Hospital
}

\author{
Masoud, A., M; Nour Eldein , S., A; Abd Elrady , S., Khames , M., A \& Mohamed , E., M . \\ Assistant Lecturer of Obstetrics and Gynecological Nursing -Faculty Of Nursing - Assiut University \\ Professor of Obstetrics and Gynecological Nursing -Faculty of Nursing - Zagazig University \\ Professor of Obstetrics and Gynecological -Faculty of Medicine - Assiut University \\ Assistant Professor of Obstetrics and Gynecological Nursing -Faculty of Nursing - Assiut University \\ Lecturer of Obstetrics and Gynecological Nursing -Faculty of Nursing - Assiut University
}

\begin{abstract}
Minor complications are more common than major complications when having a Cesarean Section (C.S) may affect either the mother or the infant. Maternal morbidity following C.S is estimated to be eight times greater than that following vaginal delivery. objective: to identify postnatal health problems experienced by women delivered by C.S. Methods: A prospective study design was adopted in this study to achieve the stated aim, a purposive sample of all puerperal women $(n=330)$ puerperal women and their newborns' who had C.S delivery in the postpartum wards of Obstetrics Department, Women's Health Center, Assiut University Hospital, Egypt. The Women's Health Center .Results: minor problems were reported by $88.8 \%$ of the puerperal women. (during $1^{\text {st }}$ visit) and $74.2 \%$ during $2^{\text {nd }}$ visit. Conclusion: the overall incidence of minor health problems following C.S is occurred among the majority of women $(89.0 \%)$.
\end{abstract}

\section{Key Words: Cesarean Section (C.S), Health Problem, Postpartum, Minor Problems}

\section{Introduction}

The postpartum is the most challenging time for the mothers who deliver caesarean babies, since it is one of the major surgeries where both mother and a baby can be at risk (Rock, 2005). The rate of Caesarean sections between $10 \%$ and $15 \%$ of all births in developed countries. In 2004, the Caesarean rate was about $20 \%$ in the United Kingdom, while the Canadian rate was $22.5 \%$ in 2001-2002 (Stephen, 2009).

More than $70 \%$ of maternal deaths occur in the postpartum period, especially in developing countries due to a number of problems, $77 \%$ of these complications occur during or shortly after childbirth (within 24 hours). Such as postpartum hemorrhage, puerperal infection and hypertensive disease (Jhon \& Sons, 2007).

Women undergoing C.S have 5 to 20 folds greater risk for infection and other common complications such as fever, urinary tract infections, bacterimea, endometritis and thrombophlepitis, compared with a vaginal delivery (Jhon \& Sons, 2007). Also the women experiencing C.S have reported higher levels of tiredness, breastfeeding problems, constipation, depression, headache, difficulty voiding, abnormal bleeding, urinary tract infection, abdominal pain, and vaginal discharge than their counterparts who had a spontaneous vaginal birth (Hannah, 2007). Skilled care and early identification of problems which arise during this period could reduce the incidence of deaths and disabilities, that is consider as a single most important intervention for preventing maternal and newborn morbidities and mortalities .

Significance of the study

Cesarean section deliveries are more likely to be associated with increased mortality and morbidity both for mother and the baby compared to women who deliver vaginally (Alexander, 2006). The

Egyptian Demographic Health Survey (EDHS) conducted in Egypt 2005 obtained information on the incidence of C.S. It showed that one-fifth $(20.0 \%)$ of deliveries were by C.S. At Assuit, according to the registries of the University Hospital, C.S rate was $45.8 \%$ in 2010 .

Thus there is critical need for early detection, monitoring and providing good quality care of postpartum health problems that can have devastating effect on the mother and her newborn during this period. In addition, improving nurses knowledge and skills related to nursing care in C.S is deemed necessary to mitigate the mortality and morbidity risks that may be encountered among parturient women and their newborn babies.

\footnotetext{
Aim of the study

The aim of this study was to identify postnatal health problems experienced by women delivered by C.S and her newborn, and to propose a nursing protocol to meet the needs of the post cesarean women during the puerperium.
} 


\section{Subject and methods}

•Research design: A prospective study design was adopted in this study to achieve the stated aim.

- Setting: This study was conducted in the postpartum wards of Obstetrics Department, Women's Health Center, Assiut University Hospital, Egypt. The Women's Health Center Sample: A purposive sample of all puerperal women $(n=330)$ puerperal women and their newborns' who had C.S delivery in the study settings were recruited for this study, according to the following criteria was recruited.

Inclusion criteria: Gestational age was more than 28 weeks, either primiparous or multiparous, whether elective or emergency, With any type of C.S.

Exclusion criteria: Presence of any psychological problems, women with perinatal and neonatal deaths

Tools of the study: Data collection was done through the use of the following tools:

\section{1- Structured interviewing sheet:}

This sheet was developed by the researcher to collect data related to :

-Socio-demographic data. Obstetric profile, current antenatal condition and Current C.S delivery.

\section{2- Immediate Postpartum Assessment:}

This part was developed by the researcher to collect data related to the condition of the woman immediately after delivery i.e. during the fourth stage of labor; until patient's discharge, as vital signs, intake and output, general and local condition of the mother as well as her new born.

\section{3- Follow up sheet:}

This sheet was used to record data related to postoperative period and any complications that have arisen. Follow up started during the first postnatal visit (12 days of the puerperium) and second visit (40 Day of the puerperium). Follow up sheet included patient's condition (vital signs, breasts, wound, uterus, lochia, perineum, lower extremities and elimination) and problems encountered. Newborn assessment, included assessment of vital signs, head, chest, abdomen, genitalia and skin condition was also done.

\section{Administrative design.}

- An official permission was granted by submission of an official letter from the Faculty of Nursing to the responsible authorities of the study setting to obtain the permission for data collection.

Field study

- Data collection took a period of nine months from the first of January 2010 to the end of September 2010. After getting the official permission the pilot testing of the study tools was done and analyzed
The present study was carried out through three phases as follows

1-Interview phase: in which all parturient women who were undergoing C.S were interviewed (structured interview) to collect data related to their socio-demographic characteristics, obstetric profile, current pregnancy and labor condition. Personal interview took 10 minutes for each one.

2-Assessment phase: In this phase, the researcher together with the on- duty physician started the examination of the parturient woman, immediately after the C.S delivery i.e. during the fourth stage of labor. Woman general and local condition was assessed; vital signs, uterus, lochia, intake and output...etc as well as the newborn condition. Problems encountered were recorded and reported.

3-Implementation of the Proposed Nursing Protocol: The implementation of the nursing protocol started during the assessment phase. Postnatal and newborn care was provided by the researcher during hospitalization and the protocol was tailored to meet each puerperal woman and her baby's needs during this stage.

- Then the investigator asked the woman to come as soon as possible to the clinic according to her reported problem to be managed properly or referred if needed. Women were followed up after their discharge, and asked to attend the out patient clinic on the "12th day" and the end of the puerperium" 40th day", whether they have problems or not.

- During these 2 contacts (Follow-up visits) the investigator assessed general condition of the mother such as (Vital signs, breast status, wound condition, uterus, lochia, perineum, nutritional status, elimination and hygiene) and her newborn as (cord condition, hygiene, feeding, sleeping and clothing) in the out patient clinic and asked her if she had any problem either for herself or her newborn and managed it or referred them if needed according to their problem. . 


\section{Results:}

Table 1. Sociodemographic characteristics of puerperal women

\begin{tabular}{|c|c|c|}
\hline Sociodemographic characteristics & $(\mathbf{N})$ & $(\%)$ \\
\hline Age $($ mean+SD) & \multicolumn{2}{|c|}{$25.85+4.8155$} \\
\hline$<20$ & 27 & 8.3 \\
\hline 20- & 213 & 64.5 \\
\hline $30+$ & 90 & 27.2 \\
\hline \multicolumn{3}{|l|}{ Occupation } \\
\hline - $\quad$ Housewife & 302 & 91.5 \\
\hline - $\quad$ Employer & 28 & 8.5 \\
\hline \multicolumn{3}{|l|}{ Education } \\
\hline - $\quad$ Illiterate & 97 & 29.4 \\
\hline - $\quad$ Read and write & 12 & 3.6 \\
\hline - $\quad$ Primary school & 11 & 3.3 \\
\hline - $\quad$ Preparatory school & 40 & 12.1 \\
\hline - $\quad$ Secondary school & 124 & 37.6 \\
\hline - University & 46 & 13.9 \\
\hline \multicolumn{3}{|l|}{ Residence } \\
\hline - Urban area & 90 & 27.3 \\
\hline - $\quad$ Rural area & 240 & 72.7 \\
\hline
\end{tabular}

Fig. 1 Type of C.S in both groups

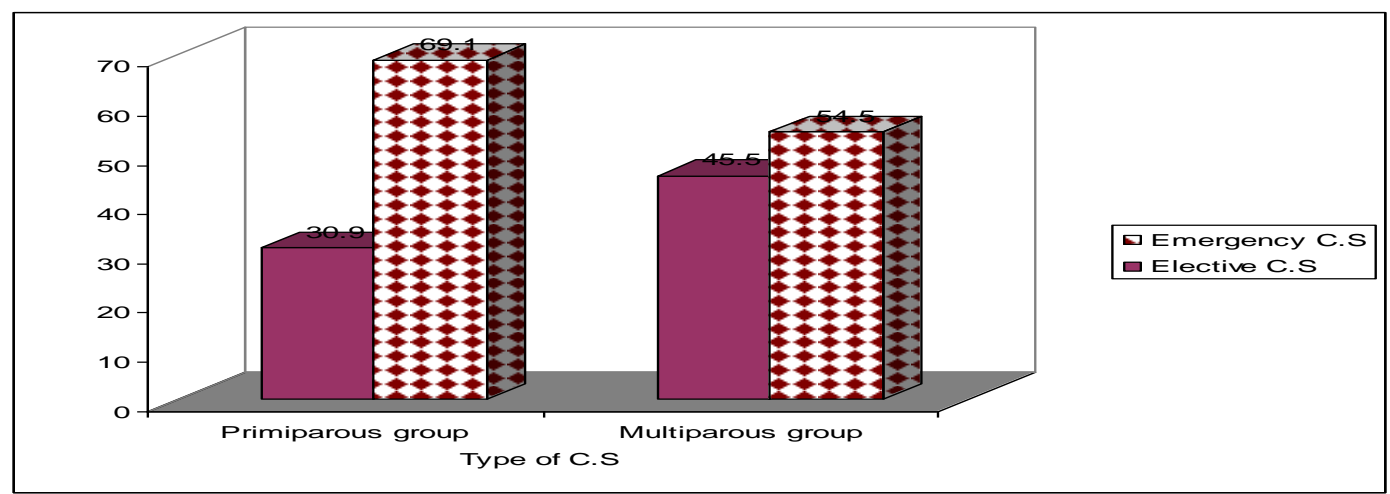

Fig. 2 Type of C.S in both groups

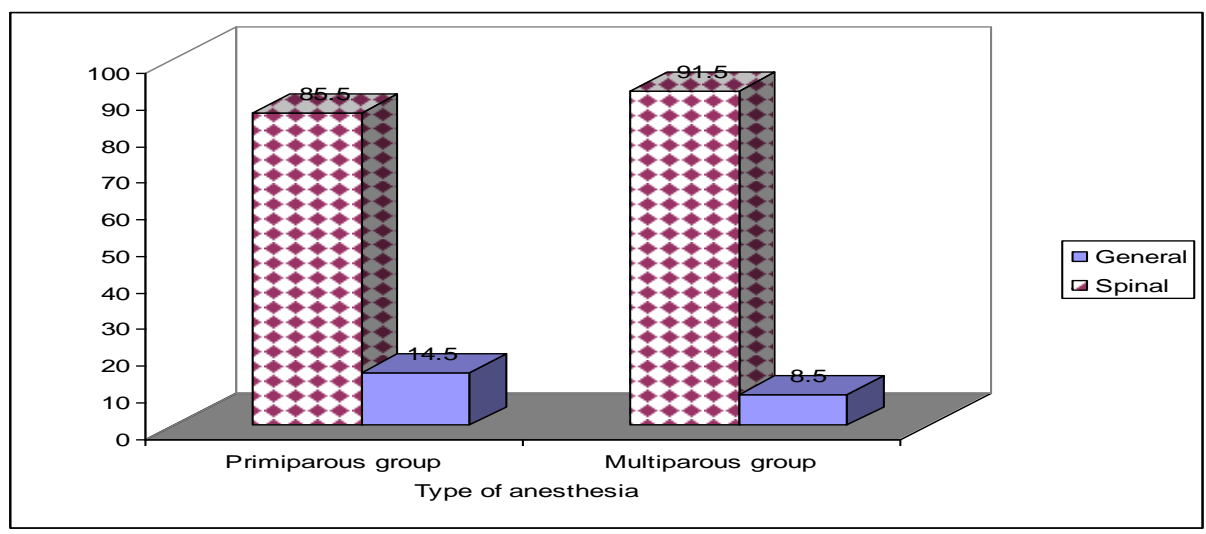


Table 2. Minor health problem encountered among the studied women:

\begin{tabular}{|c|c|c|c|c|c|c|}
\hline \multirow[t]{2}{*}{ Items } & \multicolumn{2}{|c|}{$\begin{array}{ll}\text { During hospitalization } \\
\mathrm{n}=(\mathbf{3 3 0})\end{array}$} & \multicolumn{2}{|c|}{$\begin{array}{l}\text { During } 1^{\text {st }} \text { visit } \\
n=(330)\end{array}$} & \multicolumn{2}{|c|}{$\begin{array}{l}\text { During } 2^{\text {nd }} \text { visit } \\
n=(295)\end{array}$} \\
\hline & $(\mathbf{N})$ & $(\%)$ & (N) & $(\%)$ & $(\mathbf{N})$ & $(\%)$ \\
\hline 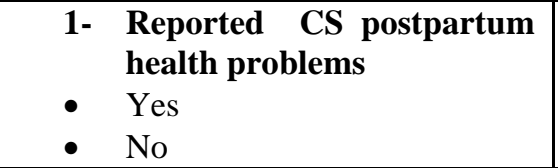 & $\begin{array}{l}312 \\
18\end{array}$ & $\begin{array}{l}94.5 \\
5.5\end{array}$ & $\begin{array}{l}293 \\
37\end{array}$ & $\begin{array}{l}88.8 \\
11.2\end{array}$ & $\begin{array}{l}219 \\
76\end{array}$ & $\begin{array}{l}74.2 \\
25.8\end{array}$ \\
\hline \multicolumn{7}{|l|}{ 2.Type of these problems @ } \\
\hline General problems & 261 & 79.1 & 227 & 68.8 & 130 & 44.1 \\
\hline$\Delta$ GIT problems & 248 & 75.2 & 68 & 20.6 & 27 & 9.2 \\
\hline a Incision problems & 163 & 49.4 & 183 & 55.5 & 55 & 18.6 \\
\hline$\square$ Muscle skeletal problems & 128 & 38.8 & 206 & 62.4 & 100 & 33.9 \\
\hline$\diamond$ Breast problems & 45 & 13.6 & 68 & 20.6 & 27 & 9.2 \\
\hline + Others & 38 & 11.5 & 39 & 11.8 & 16 & 5.4 \\
\hline
\end{tabular}

+ Others (itching, leg pain/edema, dysurea/renal pain and hypotension and hypertension

$\Delta$ GIT problems ( nausea/ vomiting, abdominal distention /pain, constipation).

- General problems (Fatigue, headache).

Muscle skeletal problems (Backache, neck/ shoulder pain)

$\diamond \quad$ Breast problems (Cracked / sore nipple, Flat nipple Inverted nipple, mastitis and breast abscess, insufficient milk flow

- Incision problems (pain, tenderness/numbness around wound area, oozing of blood from the wound, skin rash, redness, separation of wound edges ).

@Not mutually exclusive

The minor health problem encountered among C.S puerperal women are displayed in

Table 3. Newborn health problems (during hospitalization) among both groups:

\begin{tabular}{|c|c|c|c|c|c|}
\hline \multirow[t]{2}{*}{ Newborn health problems } & \multicolumn{2}{|c|}{$\begin{array}{c}\text { Primiparous group } \\
\text { N (165) }\end{array}$} & \multicolumn{2}{|c|}{$\begin{array}{c}\text { Multiparous group } \\
\text { N(165) }\end{array}$} & \multirow[t]{2}{*}{ p.value } \\
\hline & $(\mathbf{N})$ & $(\%)$ & $(\mathbf{N})$ & $(\%)$ & \\
\hline $\begin{array}{l}\text { 1. Reported current newborn problems } \\
-\quad \text { Yes } \\
-\quad \text { No }\end{array}$ & $\begin{array}{l}87 \\
78\end{array}$ & $\begin{array}{l}52.7 \\
47.3\end{array}$ & $\begin{array}{l}85 \\
80\end{array}$ & $\begin{array}{l}51.5 \\
48.5\end{array}$ & 0.866 \\
\hline \multicolumn{6}{|l|}{ 2.Type of these problems } \\
\hline - Physiological jaundice & 40 & 24.2 & 33 & 20 & \multirow[t]{8}{*}{0.764} \\
\hline - $\quad$ Pathological jaundice & 0 & 0.0 & 0 & 0.0 & \\
\hline - Respiratory problems & 32 & 19.4 & 36 & 21.8 & \\
\hline - Gastrointestinal problems & 18 & 10.9 & 15 & 9.1 & \\
\hline - Congenital anomalies & 2 & 1.2 & 3 & 1.8 & \\
\hline - $\quad$ Cord bleeding & 0 & 0.0 & 0 & 0.0 & \\
\hline - $\quad$ Cord infection & 1 & 0.6 & 0 & 0.0 & \\
\hline - $\quad$ Others & 6 & 3.6 & 8 & 4.8 & \\
\hline
\end{tabular}

Others (eye infection, hyperthermia, head injury, urine retention, polydactyl and Mongolian baby ).

Some of newborn had more than one problem. 
Table.4 Newborn health problems (during $1^{\text {st }}$ visit) among both groups:

\begin{tabular}{|c|c|c|c|c|c|}
\hline \multirow[t]{2}{*}{$\begin{array}{l}\text { Newborn health problems } \\
\text { (during } 1^{\text {st }} \text { visit) }\end{array}$} & \multicolumn{2}{|c|}{$\begin{array}{l}\text { Primiparous group } \\
\text { N (165) }\end{array}$} & \multicolumn{2}{|c|}{$\begin{array}{l}\text { Multiparous group } \\
\mathrm{N}(\mathbf{1 6 5})\end{array}$} & \multirow[t]{2}{*}{ p.value } \\
\hline & $(\mathbf{N})$ & $(\%)$ & $(\mathbf{N})$ & $(\%)$ & \\
\hline $\begin{array}{l}\text { 1.Reported newborn problems(during } \mathbf{1}^{\text {st }} \text { visit) } \\
\text { - Yes } \\
\text { - No } \\
\text { - } \quad \text { Die }\end{array}$ & $\begin{array}{l}132 \\
30 \\
3\end{array}$ & $\begin{array}{l}80.0 \\
18.2 \\
1.8\end{array}$ & $\begin{array}{l}122 \\
39 \\
4\end{array}$ & $\begin{array}{l}73.9 \\
23.7 \\
2.4\end{array}$ & 0.425 \\
\hline \multicolumn{5}{|l|}{ 2.Type of these problems } & \multirow{13}{*}{0.084} \\
\hline • Physiological jaundice & 55 & 33.3 & 39 & 23.6 & \\
\hline - $\quad$ Pathological jaundice & 0 & 0.0 & 3 & 1.8 & \\
\hline - $\quad$ Respiratory problem & 38 & 23 & 28 & 17 & \\
\hline - $\quad$ Constipation & 34 & 20.6 & 29 & 17.6 & \\
\hline - $\quad$ Diarrhea & 13 & 7.9 & 11 & 6.7 & \\
\hline - $\quad$ Vomiting & 64 & 38.8 & 50 & 30.3 & \\
\hline - $\quad$ Abdominal distention & 71 & 43 & 29 & 17.6 & \\
\hline - $\quad$ Colic & 82 & 49.7 & 41 & 24.8 & \\
\hline - $\quad$ Cord bleeding & 12 & 7.3 & 14 & 8.5 & \\
\hline - $\quad$ Cord infection & 37 & 22.4 & 29 & 17.6 & \\
\hline - $\quad$ Delay in cord separation & 54 & 32.7 & 30 & 18.2 & \\
\hline - $\quad$ Others & 34 & 20.6 & 30 & 18.2 & \\
\hline
\end{tabular}

Others(diaper rash, oral infection, skin rash, eye infection, umbilical hernia, dysurea/urine retention and hyperthermia). Some of newborn had more than one problem.

Table 5 Newborn health problems (during $2^{\text {nd }}$ visit) among both groups

\begin{tabular}{|c|c|c|c|c|c|}
\hline \multirow[t]{2}{*}{ Newborn health problems(during $2^{\text {nd }}$ visit) } & \multicolumn{2}{|c|}{$\begin{array}{c}\text { Primiparous } \\
\text { group N (150) }\end{array}$} & \multicolumn{2}{|c|}{$\begin{array}{l}\text { Multiparous } \\
\text { group N(145) }\end{array}$} & \multirow[t]{2}{*}{ p.value } \\
\hline & $(\mathbf{N})$ & $(\%)$ & $(\mathbf{N})$ & $(\%)$ & \\
\hline $\begin{array}{l}\text { 1. Reported newborn problems(during } \mathbf{2}^{\text {nd }} \text { visit) } \\
\text { - Yes } \\
\text { - No } \\
\text { - Die } \\
\end{array}$ & $\begin{array}{c}110 \\
40 \\
0 \\
\end{array}$ & $\begin{array}{c}73.3 \\
26.7 \\
0.0 \\
\end{array}$ & $\begin{array}{c}125 \\
18 \\
2 \\
\end{array}$ & $\begin{array}{c}86.2 \\
12.4 \\
1.4 \\
\end{array}$ & $* 0.004$ \\
\hline \multicolumn{6}{|c|}{ 2.Type of these problems } \\
\hline - Jaundice & 0 & 0.0 & 0 & 0.0 & \multirow{11}{*}{$* 0.001$} \\
\hline - $\quad$ Respiratory problem & 5 & 3 & 3 & 1.8 & \\
\hline - Constipation & 4 & 2.4 & 4 & 2.4 & \\
\hline - $\quad$ Diarrhea & 40 & 24.2 & 53 & 32.1 & \\
\hline - $\quad$ Vomiting & 21 & 12.7 & 43 & 26.1 & \\
\hline - Abdominal distention & 25 & 16.6 & 20 & 13.7 & \\
\hline - $\quad$ Colic & 72 & 43.6 & 61 & 37 & \\
\hline - $\quad$ Cord infection & 58 & 35.2 & 49 & 29.7 & \\
\hline - $\quad$ Oral infection & 57 & 34.5 & 68 & 41.2 & \\
\hline - $\quad$ Eye infection & 14 & 8.5 & 28 & 17 & \\
\hline - $\quad$ Others & 47 & 28.5 & 27 & 16.4 & \\
\hline
\end{tabular}

Others (diaper rash, dysurea/urine retention, skin rash, umbilical hernia and hyperthermia).

Some of newborn had more than one problem.

(15 women primiparous and 20 women multiparous defaulted from the second visit of follow-up).

(*)significant statistical difference. $(p<0.05)$. 
Table 1. describes the sociodemographic characteristics of women in the study sample. About two thirds of women $(64.5 \%)$ were between $20-30$ years and more than one fourth $(27.2 \%)$ of them were 30 years and more, with mean (SD) $25.85+4.8$ years. Regarding education, the highest percentage had secondary or university education $(51.5 \%)$, while $29.4 \%$ were illiterate. The majorities was housewives $(91.5 \%)$ and were living in rural areas $(72.7 \%)$.

Fig. 1 : This figure show that slightly more than half of women in both groups had an emergency C.S $(69.1 \%$ vs. $54.5 \%)$ with significant statistical difference

Fig. 2: This figure illustrate that C.S order in multiparous group was more than one third of women underwent C.S for the second time $(38.2 \%)$ followed by $(32.7 \%)$ of them had C.S for the first time. While nearly less than one fourth of women had their third C.S and the rest of them had fourth and fifth C.S $(10.3 \%)$.

table 2. The main problem was mostly the general problems $(79.1 \%)$ as; fatigue and headache. Approximately equal proportion (75.2\%) suffered from GIT problems such as; nausea and vomiting, abdominal distension and constipation during hospitalization .meanwhile during $1^{\text {st }}$ visit the most commonly reported problems were that of general problems $(68.8 \%)$ followed by muscle skeletal problems (62.4\%), incisional problems $(55.5 \%)$, breast problems $(32.4 \%)$ and one fifthe of the women $(20.6 \%)$ having gastrointestinal problems.

In the $2^{\text {nd }}$ visit more than two fifth of the studied women $(44.1 \%)$ complained of general problems, followed by muscle skeletal problems (33.9\%), incisional problems (18.6\%) in the form of pain, tenderness/numbness around wound area, incision itching oozing of purulent fluid from the wound, skin rash/redness/hotness around the wound edges and separation of wound edges.

Table 3 shows that there were no significant statistical difference as regarding to newborn health problems among both groups and the most common types of these problems were physiological jaundice (24.2\% vs. $20 \%$ ) followed by respiratory problems (19.4\% vs. $21.8 \%)$ and gastrointestinal problems (10.9\% vs. $9.1 \%)$. The most common others problems that reported by among both groups were [ eye infection $(2.4 \%)$ vs. (3.6\%) respectively.]

table 4 noticed that there were no significant statistical difference among both groups concerning to the newborn health problems (during $1^{\text {st }}$ visit) . Additionally the most common types of these problems were [colic (49.7\%), abdominal distention (43.0\%) and vomiting (38.8\%)] among newborn of primiparous women. Meanwhile [vomiting (30.0\%), colic (24.8\%) and physiological jaundice (23.6\%)] were the most common types of problems encountered among newborn of multiparous women. Also oral infection $(9.6 \%)$ followed by diaper rash $(7.2 \%)$ respectively were the most common others problems among both groups.

Table 5 : This table points to presence of significant statistical difference (0.001) among both groups as regarding to newborn health problems (during $2^{\text {nd }}$ visit). Also demonstrates that the colic(43.6\%), cord infection $(35.2 \%)$ and oral infection $(34.5 \%)$ were the most frequent problems repeated among primiparous group while in the other group oral infection (41.2\%) followed by colic (37\%) were the most common problems in this period. Diaper/skin rash $(16.6 \%$ vs. $13.7 \%$ respectively) were the most common others problems reported among both groups.

\section{Discussion:}

According to the present study findings, The majority of the studied women were housewives and living in rural areas. In the same line, these findings were also in congruence with Mahmoud (2007) \& Abd Elhamid (2006), who clarified that the highest percentage of women were housewives and living in rural area. This finding could be because women in rural areas have little access to antenatal care. According to the present study nearly more than half of women in both groups had an emergency C.S $69.1 \%$ vs. $54.5 \%$ with significant statistical difference. In congruence with these findings, Abd El-hamid (2006) and Mahmoud (2007), have showen that the majority of C.S were emergency.

As for type of anesthesia, spinal anesthesia received by highest percentage of women $85.5 \%$ vs. $91.5 \%$. But present study could not revealed any significant statistical difference among both groups. Similarly Mahmoud (2007), reported that the majority of women $90.3 \%$ received spinal anesthesia. Also Pitt (2001), who studied (post C.S complications) reported that one third of the sample $30 \%$ were received spinal anesthesia

The most common minor health problems encountered among women during hospitalization in the present study were the general problems $(79.1 \%)$ followed by GIT problems, incision problems and muscle skeletal problems. Eugene (2008), examined "Mothers reports of their postpartum experiences with pain" stratified by method of delivery and pointed that about $79 \%$ of mothers who had a C.S experiencing pain from their surgery in the first 2 months after birth. Kashaninia (2007), studied "the effect of discharge planning on physical status of Iranian mothers in the postpartum period" and found no significant differences were observed in some 
others complications, such as abnormal nipple, nipple fissure, abnormal uterine size, dysuria, frequency and incontinence of urine, chronic fatigue and sleep disorders, and mothers' re-hospitalization rate at sixth week.

There were no significant statistical difference as regarding to newborn health problems among both groups as revealed in our study, and the most common types of these problems were physiological jaundice $24.2 \%$ vs. $20 \%$ followed by respiratory problems $19.4 \%$ vs. $21.8 \%$ and gastrointestinal problems $10.9 \%$ vs. $9.1 \%$.

The present study revealed that there were significant statistical difference among both groups as regarding to newborn health problems (during $1^{\text {st }} \& 2^{\text {nd }}$ visit) Ransjo et al., (1998), reported in their study that the infant health problems pattern was

similar in the both groups with no significance difference at day 42 postpartum

\section{Conclusions :}

The total incidence of minor problems occurred among the majority of women with early problems being more frequent compared to problems during $1^{\text {st }}$ and $2^{\text {nd }}$ visits.

\section{Recommendations:}

A training program for all nurses about postpartum health problems and postpartum care that needed for the women undergoing C.S and further studies in different settings were recommended in this study.

\section{Reference:}

1. Abd-Elhamid A., M., (2006): Post operative complications following Cesarean Section delivery in Zagazig: prevalence and nursing implication. Thesis of philosophy degree in maternal newborn nursing, Zagazig University.

2. Alexander, J. M., Leveno, K. J., Hauth, J., Landon, M. B., Thom, E., Spong, C. Y., et al. (2006): Fetal injury associated with cesarean delivery. Obstet Gynecol, 108(4), 885-890.

3. Egyptian Demographic Health Survey (EDHS), maternal health care ,National population council,Cairo , Egypt ,Marco, USA,2005 pp129 -132

4. Eugene Declercq, PhD, Deborah K. Cunningham, MN, MPH, Cynthia Johnson, MD, and Carol Sakala, PhD, MSPH(2008):Mothers' Reports of Postpartum Pain

5. Hannah ME, Hannah WJ, Hodnett ED, Chalmers B, Kung R, Willan A, et al.(2002): Outcomes at 3 months after planned cesarean vs. planned vaginal delivery for breech presentation at term: The International Randomized Term Breech Trial. JAMA 2002; 287: 1822-31.

6. Jhon W., and Sons, L., (2007): The Cochrane collaboration, prophylaxis for Cesarean Section, review (2).

7. Kashaninia Zahra, MSc; Sajedi Firoozeh, MD, Ashraf Khoramirad, (2007): The effect of discharge planning on physical status of Iranian mothers in the postpartum period, February 2007 - Volume 1, Issue 1

8. Lefty L., Apozzio J and Vintziles S. (1996) :operative obstetrics $2^{\text {nd }}$ ed., New York ,pp 401

9. Mahmoud.G.A.,(2007): The prevalence of women undergoing cesarean section in Women's Health center, Assiut University Hospital, thesis of Doctorate in obstetrics and gynecology

10. Makhlough E., M.,(2007) : Normal versus high risk postpartum new mothers randomized clinical trial. Thesis of doctorate degree of Nursing sciences.Assiut University

11. Ransjo A., K Chintu, B., Eriksson, B Susu, K Christensson and VK Diwan (1998): Maternal and infant health problems after normal childbirth : a randomized controlled study in Zambia, J Epidemiology Community Health 1998; 52 385-391.

12. Rock, J.A., (2005): when you need an operation , cesarean section . American College of Surgeons , Chicago, http://www.facs.com

13. Stephen J. Robson, MPH, MD, F, Woo Syong Tan, MBBS, (2009): Estimating the Rate of Cesarean Section by Maternal Request: Anonymous Survey of Obstetricians in Australia

14. Uygur D., Tapisiz $O$ and Mungun $T$ (2005)multiple repeat cesarean section maternal and neonatal outcome I J O Obs\&Gyn, 89:284285

15. World Health Organization (WHO) (2009): Monitoring emergency obstetric care: A handbook. France: World Health Organization

16. World Health Organization (WHO), (2006): Maternal and child health Relevance and importance of quality postpartum care, practical guide. 